\title{
EQUAÇÕES ESTRUTURAIS APLICADAS À SATISFAÇÃO DOS ALUNOS: UM ESTUDO NO CURSO DE CIÊNCIAS CONTÁBEIS DA UNIVERSIDADE FEDERAL DE SANTA MARIA
}

\section{STRUCTURAL EQUATIONS APPLIED TO STUDENT SATISFACTION: A STUDY IN THE ACCOUNTANCY COURSE AT THE FEDERAL UNIVERSITY OF SANTA MARIA}

\author{
KELMARA MENDES VIEIRA \\ Doutora em Administração e Professora Adjunta \\ do Departamento de Ciências Administrativas - PPGAVCCSH \\ da Universidade Federal de Santa Maria \\ E-mail: kelmara@smail.ufsm.br
}

\author{
FELIPE TAVARES MILACH \\ Mestrando em Administração pelo Programa de \\ Pós-Graduação em Administração da Escola de Administração \\ da Universidade Federal do Rio Grande do Sul \\ E-mail: felipemilach@terra.com.br
}

\author{
DANIELA HUPPES \\ Mestre em Administração \\ pelo Programa de Pós-Graduação em Administração \\ da Universidade Federal de Santa Maria \\ E-mail: danielahuppes@terra.com.br
}

\section{RESUMO}

O presente estudo tem como objetivo avaliar os determinantes da satisfação geral dos alunos de Ciências Contábeis da Universidade Federal de Santa Maria em relação ao Curso. Para tanto, utilizaram-se os construtos Envolvimento do Professor, Envolvimento do Estudante, Interação Estudante-Professor, Demandas do Curso e Organização do Curso, apresentados no modelo de equações estruturais de Paswan e Young (2002). A esse modelo foi acrescentada a variável Satisfação Geral, a fim de verificar se a satisfação dos estudantes em relação ao Curso pode ser explicada pelos construtos. $\mathrm{O}$ instrumento de coleta de dados utilizado foi um questionário composto de 42 questões, aplicado a 224 acadêmicos. O modelo de equações estruturais, inicialmente proposto, foi testado e alterado de acordo com os resultados obtidos nas análises. Procurando tornar o modelo mais adequado, optou-se por se retirar o construto Demandas do Curso. Os resultados do modelo de mensuração demonstraram a validade dos construtos Envolvimento do Professor, Interesse do Estudante, Interação Professor-Estudante e Organização do Curso. No modelo, são comprovadas cinco das oito hipóteses estabelecidas originalmente e indicaram a retirada do construto Demandas do Curso. O modelo estrutural testou oito hipóteses, das quais cinco foram confirmadas. O modelo ajustado mostrou-se adequado para mensurar a Satisfação Geral dos estudantes do Curso de Ciências Contábeis da Universidade Federal de Santa Maria, comprovando que os construtos Envolvimento do Professor e Interesse do Estudante influenciam positivamente a Satisfação Geral do estudante em relação ao curso.

Palavras-chave: Equações Estruturais. Satisfação Geral. Acadêmicos de Ciências Contábeis.

\section{ABSTRACT}

The objective of this paper is to evaluate the factors determining general satisfaction among Accountancy students at the Federal University of Santa Maria, in relation to the course. Therefore, Teacher Involvement, Student Involvement, Teacher-Student Interaction, Course Demands and Course Organization constructs were used and presented in the structural equation model of Paswan and Young (2002). The variable General Satisfaction was added to this model to verify if student satisfaction in relation to the course can be explained through these constructs. Data were collected through a questionnaire composed of 42 questions, answered by 224 students. The initially proposed structural equation model was tested and altered in accordance with the analysis results. To make a more adequate model, the construct of Course Demands was eliminated. The structural model tested eight hypotheses, five of which were confirmed. The adjusted model proved to be adequate for measuring General Satisfaction of Accountancy students at the Federal University of Santa Maria, reaffirming that the constructs Teacher Involvement and Student Interest positively influenced the General Satisfaction of the student in relation to the course.

Keywords: Structural Equation. General Satisfaction. Accounting Students. 


\section{INTRODUÇÃO}

O aumento da quantidade de Instituições de Ensino Superior (IES) no país, principalmente a partir da vigência da Lei de Diretrizes e Bases da Educação Nacional (Lei 9394/96), altera o panorama nacional de ensino e cria mecanismos que permitem à sociedade fazer comparações de desempenho entre as instituições. Isso, conseqüentemente, obriga as IES a se preocuparem, cada vez mais, com os cursos oferecidos.

Da mesma forma que qualquer outra organização moderna, as Instituições de Ensino Superior devem cumprir exigências de qualidade, competência e produtividade. Essas instituições se deparam com uma necessidade crescente de conhecer o seu público alvo, para que possam oferecer programas e serviços de acordo com as exigências do mercado e do perfil de seus alunos.

Nesse cenário, a qualidade dos serviços oferecidos e a satisfação dos discentes são fundamentais para as Instituições de Ensino Superior que buscam sobreviver no mercado educacional. A qualidade do curso de graduação e 0 envolvimento e a satisfação dos acadêmicos com o curso são fatores que determinam o perfil e o desempenho dos profissionais que ingressarão no mercado de trabalho; e a formação de profissionais competentes é uma cobrança da sociedade. Assim, os alunos devem ser o centro das atenções das IES que almejam melhorar seus cursos, de forma a assegurar uma formação final de maior qualidade.

Outros dois indicadores críticos, principalmente para uma instituição pública, são: o tempo que os alunos levam para concluir o curso e o número de desistentes. Esses índices também são influenciados pelo nível de satisfação do corpo discente, pois quanto mais satisfeito ele estiver, menor será o número de desistentes e mais rapidamente os estudantes concluirão o seu curso. Isso garante um retorno maior para a sociedade que mantém as Instituições de Ensino Superior Públicas. Logo, monitorar os níveis de satisfação dos acadêmicos, avaliando o seu interesse e o dos professores, as formas de ensino, os currículos e a organização do curso, é uma maneira de garantir a satisfação das necessidades tanto dos alunos como da sociedade.

Em meio a tais reflexões, o objetivo deste trabalho é avaliar quais fatores determinam a Satisfação Geral dos alunos de Ciências Contábeis da Universidade Federal de Santa Maria em relação ao Curso. Para atingir tal objetivo, a pesquisa, aplicada através de um questionário, testou os construtos Envolvimento do Professor, Envolvimento do Estudante, Interação Estudante-Professor, Demandas do Curso e Organização do Curso, apresentados no modelo de equações estruturais de Paswan e Young (2002). A esses construtos foi acrescentada a variável Satisfação Geral, para verificar se a satisfação dos estudantes em relação ao Curso pode ser explicada pelos construtos propostos.

Como pode ser constatado nas publicações nacionais e internacionais, a maioria das pesquisas sobre avaliação e satisfação dos estudantes em relação ao seu curso de graduação usa métodos estatísticos que possibilitam examinar apenas uma única relação de cada vez, como a correlação, a regressão múltipla e análises de variância (CLAYSON; HALEY, 1990; MARKS, 2000). No entanto, o uso do modelo de equações estruturais permite ao pesquisador testar um número maior de relações entre as variáveis $e$ os construtos em análise, sendo, portanto, esse o modelo utilizado neste estudo.

O trabalho está estruturado em quatro partes. Na primeira, são expostos os construtos indicados por Paswan e Young (2002) e utilizados na pesquisa, além da variável Satisfação Geral. Após, apresentam-se os procedimentos metodológicos e a análise dos dados, que contêm a validação do modelo. Por último, expõem-se as conclusões do estudo, com as limitações e as principais contribuiç̧ões da pesquisa.

\section{DESENVOLVIMENTO DO MODELO}

A presente pesquisa foi realizada a partir dos construtos Envolvimento do Professor, Envolvimento do Estudante, Interação Estudante-Professor, Demandas do Curso e Organização do Curso, apresentados por Paswan e Young (2002). A esses construtos incluiu-se a variável Satisfação Geral, com o objetivo de verificar se os construtos analisados podem explicar a satisfação geral do acadêmico com o curso de Ciências Contábeis.

\subsection{Envolvimento do Professor e Interesse do Estudante}

O modelo de Paswan e Young (2002) considera os construtos Envolvimento do Professor e Interesse do Estudante como dados em função dos demais construtos, sendo, portanto, construtos de segunda ordem. Marsh (1982) e Cashin (1988) argumentam que é o professor e não o curso o determinante principal no resultado da avaliação dos estudantes em relação ao processo.

O construto Envolvimento do Professor diz respeito a fatores como a percepção do aluno em relação ao entusiasmo e interesse do professor, a habilidade do professor em explicar o conteúdo, utilizando exemplos e de forma que os alunos compreendam os assuntos.

Já o construto Interesse do Estudante é formado por fatores como o nível de atenção e interesse que o aluno dá às aulas e a forma como esse percebe a sua evolução intelectual ao longo do curso, tornando-se, ou não, mais competente.

Vários pesquisadores defendem que o envolvimento do professor tem grande influência no interesse do aluno e vice-versa. Cashin (1995) sugere que a motivação dos estudantes possui um papel importante no resultado da 
instrução. Clayson e Haley (1990), por outro lado, argumentam que o interesse do estudante pode ser influenciado pelo envolvimento do professor. Para esses autores, aqueles estudantes que se sentem desafiados e que percebem o seu desenvolvimento intelectual ao longo do curso tendem a compartilhar com os seus professores as razões do seu sucesso.

\subsection{Interação Professor-Estudante}

O primeiro construto apresentado é chamado Interação Professor-Estudante e pode ser representado por fatores como a oportunidade do aluno discutir, questionar e esclarecer suas dúvidas durante as aulas, bem como possuir a liberdade para expressar os seus pontos de vista.

Paswan e Young (2002) propuseram que a Interação Professor-Estudante possa influenciar as duas variáveis endógenas do estudo: o Envolvimento do Professor e o Interesse do Estudante. Já Grunenwald e Ackerman (1986), ao realizarem uma pesquisa com estudantes de administração, concluíram que a interação tem uma influência importante na efetividade do ensino. Assim, as hipóteses relacionadas a esse construto são:

Hipótese 1: Um grau mais alto de Interação ProfessorEstudante conduzirá a um nível maior de Envolvimento do Professor.

Hipótese 2: Um grau mais alto de Interação ProfessorEstudante conduzirá a um nível maior de Interesse do Estudante no curso.

\subsection{Demandas do Curso}

O construto Demandas do Curso envolve fatores como o modo com que o professor passa o conteúdo aos alunos, a validade do desenvolvimento de trabalhos em sala de aula e o nível das leituras indicadas pelo professor.

Clayson e Haley (1990) afirmam que há uma correlação negativa entre o rigor do curso e a forma como os alunos avaliam o seu aprendizado. Com base nessa informação, propõe-se a testar se:

Hipótese 3: Um nível mais alto de Demandas do Curso conduzirá a um baixo nível, percebido, do Envolvimento do Professor.

\section{PROCEDIMENTOS METODOLÓGICOS}

O estudo considerou como universo de pesquisa todos os alunos matriculados no curso de Ciências Contábeis da Universidade Federal de Santa Maria (UFSM) no segundo semestre letivo de 2006, totalizando 328 acadêmicos. Partindo do universo de pesquisa, a amostra foi formada por todos os alunos presentes em sala de aula durante duas semanas compreendidas entre os meses de janeiro e fevereiro de 2007, totalizando 224 estudantes, o equivalente a $68 \%$ do total da população.

Como instrumento de coleta de dados optou-se pela utilização de um questionário, formado por três blocos distintos de perguntas. O primeiro bloco aborda aspectos
Hipótese 4: Um nível mais alto de Demandas do Curso conduzirá a um nível mais baixo de Interesse do Estudante no curso.

\subsection{Organização do curso}

A Organização do Curso, último construto proposto no modelo de Paswan e Young (2002), avalia, entre outros aspectos, se os conceitos foram relacionados sistematicamente e a grade curricular do curso foi esboçada adequadamente. Para esse construto são indicadas as seguintes hipóteses:

Hipótese 5: Um nível mais alto da Organização do Curso conduzirá à percepção de um nível mais alto de Envolvimento do Professor.

Hipótese 6: Um nível mais alto da Organização do Curso conduzirá a um nível mais alto de Interesse do Estudante no curso.

\subsection{Satisfação}

Conforme defendem diversos autores, a satisfação dos alunos é um fator fundamental para o sucesso das Instituições de Ensino Superior (GONÇALVES FILHO et al., 2003; SOUKI; PEREIRA, 2004; CODA; SILVA, 2004; WALTER et al., 2005; DE TONI et al., 2006). A satisfação envolve o atendimento das expectativas dos acadêmicos, supondose, assim, que a ela se relaciona ao Interesse do Estudante, Envolvimento do Professor, Interação Estudante-Professor, Organização do Curso e Demandas do Curso. Portanto, o presente estudo propõe-se a testar se os construtos indicados por Paswan e Young (2002) podem ser utilizados para mensurar a Satisfação Geral dos estudantes de uma IES e formulam-se as seguintes hipóteses:

Hipótese 7: Um nível mais elevado de Envolvimento do Professor conduzirá a um nível mais alto de Satisfação Geral dos alunos em relação ao curso.

Hipótese 8: Um nível mais alto de Interesse do Estudante em relação ao curso conduzirá a uma percepção de um maior grau de Satisfação Geral.

pessoais e socioeconômicos. Nesse bloco, foram feitas questões sobre o sexo, a renda familiar e idade do respondente. O segundo questiona a condição do respondente no curso, englobando questões como o semestre cursado, a formação escolar, a forma de ingresso no curso, entre outras. E o terceiro bloco é formado por questões desenvolvidas a partir do modelo de Paswan e Young (2002), além de questões acrescentadas pelos autores. Foram acrescentadas questões em cada um dos cinco construtos propostos e uma questão sobre a Satisfação Geral dos estudantes com o curso. Para as questões desse bloco foi utilizada uma escala tipo Likert (Anexo 1). 
Tendo em vista o objetivo do trabalho optou-se pela modelagem de equações estruturais (MEE) porque, conforme destacam Hair et al. (2005), enquanto técnicas como a regressão múltipla, a análise fatorial, a análise de variância e outras avaliam uma única relação entre as variáveis dependentes e independentes, a MEE possibilita a estimação simultânea de uma série de equações múltiplas distintas, mas que se inter-relacionam. Assim, o modelo inicial a ser testado pode ser visualizado na Figura $1 \mathbf{0}$.

Para Anderson e Gerbing (1998), o modelo híbrido deve ser avaliado em dois momentos: o primeiro envolve a construção de um modelo de mensuração aceitável através de

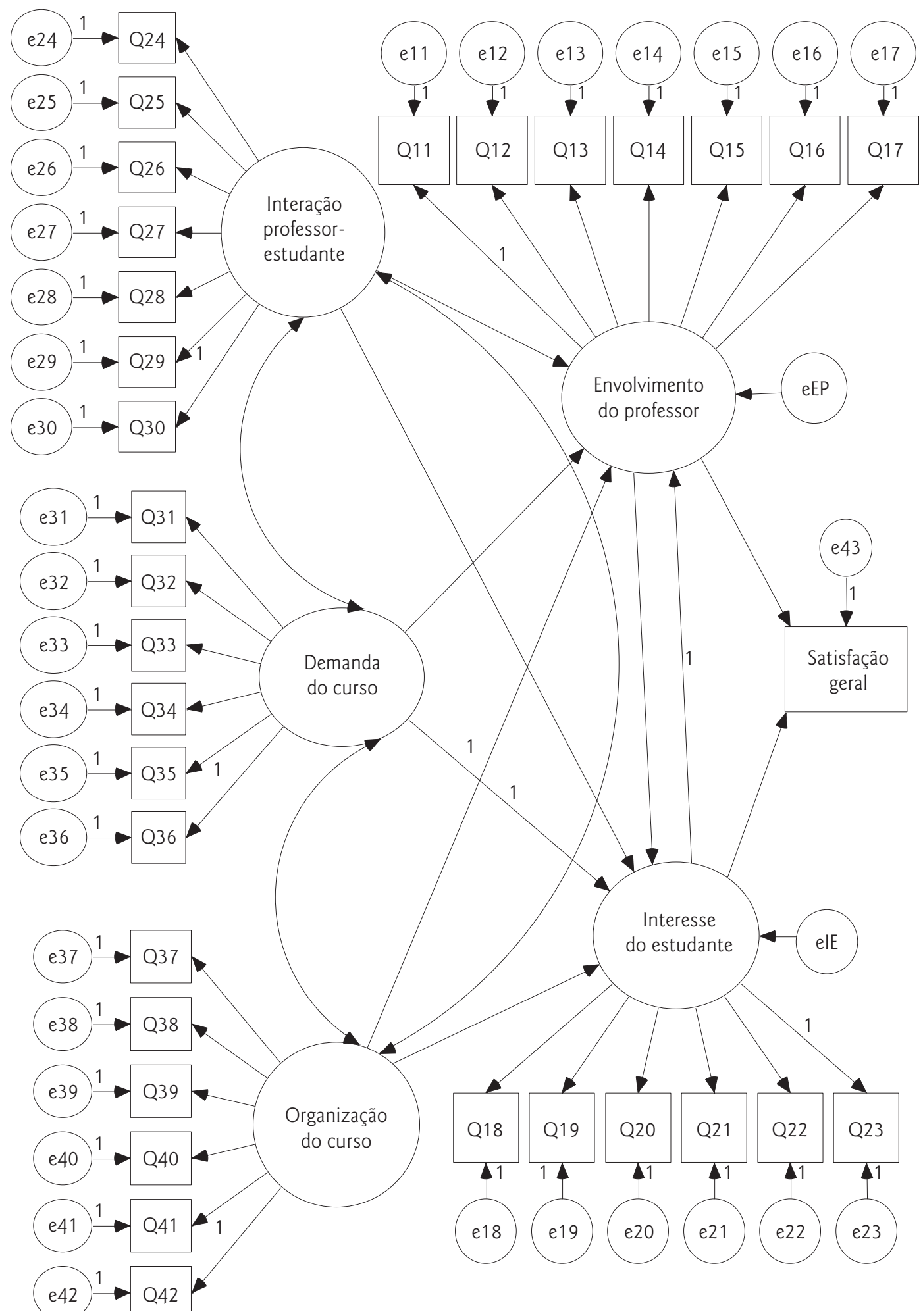

Figura 1 Modelo inicial 
uma Análise Fatorial Confirmatória. Determinado o modelo de mensuração, o segundo momento consiste em avaliar as relações entre os construtos, determinadas pelo conjunto de regressões que compõem o modelo estrutural.

Portanto, seguindo essa recomendação, a avaliação do modelo foi realizada em duas etapas. Na primeira, utilizou-se a Análise Fatorial Confirmatória (AFC) para validar os construtos. Na segunda, o modelo híbrido foi validado através dos índices de ajuste do modelo global e da significância e magnitude dos coeficientes das regressões estimadas.

De acordo com Pedhazur e Schmelkin (1991), a AFC é um modelo que procura mensurar as relações entre os indicadores (variáveis observadas) e os construtos (fatores, variáveis latentes). A utilização da AFC, na modelagem de equações estruturais, possibilita a avaliação da confiabilidade e da validade dos construtos (GARVER; NENTZER, 1999; HAIR et al., 2005). A confiabilidade indica o grau de consistência interna entre os múltiplos indicadores de um construto, referindo-se à extensão na qual um mesmo instrumento de medida produz resultados coerentes a partir de diversas mensurações (SCHUMACKER; LOMAX, 1996), e a validade refere-se à extensão na qual as medidas definem um determinado construto (CHURCHILL, 1979).

Para a validação de um construto, devem ser observadas a validade convergente, a unidimencionalidade e a confiabilidade. De acordo com Malhotra (2001), a validade convergente mede a extensão em que a escala se correlaciona positivamente com outras medidas do mesmo construto.

A validade convergente foi avaliada a partir do exame das cargas fatoriais e das medidas de ajuste. As cargas fatoriais descrevem as relações entre as variáveis observadas e o construto, gerando informações sobre a extensão na qual uma variável observável é capaz de medir um construto (SCHUMACKER; LOMAX, 1996). Além da observação da magnitude e significância estatística dos coeficientes padronizados, procurou-se analisar as medidas absolutas de ajuste e as medidas de ajuste comparativas.

As medidas absolutas de ajuste são aquelas que avaliam o grau em que o modelo global prediz a matriz de covariância ou correlação. Testou-se a validade convergente dos construtos através das seguintes medidas:

- Estatística qui-quadrado $\left(\chi^{2}\right)$ : de acordo com Hair et al. (2005), a significância das diferenças entre a matriz observada e a matriz estimada pode ser avaliada pelo $\chi^{2}$. O que se busca, na realidade, é um valor de $\chi^{2}$ não significativo dado que $\mathrm{HO}$ indica que os dados se ajustam ao modelo. No caso de o valor de $\chi^{2}$ ser significativo, alguns autores defendem que se possa dividir o seu valor pelos graus de liberdade $\left(\chi^{2} / \mathrm{GL}\right)$. Para Kline (1998), uma razão menor do que três é aceitável, já para Hair et al. (2005) esse valor deve ser igual ou inferior a cinco.

- Root Mean Squares Residual (RMR): se não houver discrepâncias entre as covariâncias observadas e aquelas determinadas no modelo, o ajuste é perfeito e tem-se RMR igual a zero. Conforme aumentam as discrepâncias, o índice aumenta. Kline (1998) considera um valor menor do que 0, 10 aceitável.

- Root Mean Square Error of Aproximation (RMSA): além das discrepâncias entre a matriz predita e a observada, leva em consideração os graus de liberdade. Para Hair et al. (2005) valores inferiores a 0,08 são considerados aceitáveis.

- Goodness-of-Fit Index (GFI): considera a quantidade de variância e covariância da matriz observada que é reproduzida pela matriz estimada (SCHUMACKER; LOMAX, 1996). Os valores geralmente variam de zero a um (ajuste perfeito), no entanto, conforme destaca Kline (1998), podem assumir valores negativos ou maiores do que um quando a amostra é pequena ou quando o modelo é sobre-identificado.

Ainda se estimou a validade convergente do construto através de medidas de ajuste comparativas. Pode-se dizer que essas medidas são aquelas utilizadas para comparar o modelo proposto com o modelo nulo. Utilizaram-se as seguintes medidas de ajuste comparativas:

- Comparative Fit Index (CFI): segundo Hair et al. (2005), trata-se de uma medida comparativa global entre os modelos estimado e nulo. De acordo com Kline (1998) valores superiores a 0,9 são desejáveis.

- Normed Fit Index (NFI): aponta a proporção em que o ajuste do modelo proposto é melhor do que o ajuste do modelo nulo. Hair et al. (2005) destacam que não existe um valor absoluto que indique um nível de ajuste aceitável, mas recomenda-se que seja superior a 0,9.

- Tucker-Lewis Index ou Non-Normed Fit Index (NNFI): deve ser interpretado da mesma forma que o NFI. O $\mathrm{NNFI}$, no entanto, inclui um ajuste para a complexidade do modelo. Recomenda-se um nível superior a 0,9 (GARVER; MENTZER, I 999; HAIR et al., 2005).

De acordo com Hair et al. (2005), após o ajuste geral do modelo ter sido avaliado, pode-se, ainda, examinar cada construto quanto à unidimensionalidade e confiabilidade. $\mathrm{A}$ unidimensionalidade é o grau em que um conjunto de itens representa apenas um construto. Já a confiabilidade, segundo Schumacker e Lomax (1996), indica o grau de consistência interna entre os múltiplos indicadores de um construto, referindo-se à extensão na qual um mesmo instrumento de medida produz resultados coerentes a partir de diversas mensurações. Para avaliar a unidimensionalidade do construto foram analisados os resíduos padronizados relativos aos indicadores de cada variável latente. De acordo com Garver e Mentzer (1999), resíduos elevados podem indicar, entre outras coisas, que os itens são inadequados. Para esse procedimento, foram considerados unidimensionais os construtos que apresentaram para todos os pares formados por variáveis observadas, resíduos padronizados menores do que $2,58(p=0,05)$. Para mensurar a confiabilidade, utilizou-se o Alfa de Crombach que, de acordo com Hair et al. (2005), deve possuir um valor superior a 0,7 . 


\section{ANÁLISE DOS DADOS}

A aplicação dos questionários foi realizada durante duas semanas entre os meses de janeiro e fevereiro de 2007, sendo abordados todos os alunos presentes em sala de aula durante esse período. Em relação à primeira parte do questionário observou-se que, dos 224 respondentes, 85 pertenciam ao turno diurno (38\%) e 139 ao noturno (62\%). Para a análise dos dados, utilizaram-se o pacote estatístico SPSS e o software para modelagem de equações estruturais Amos ${ }^{\mathrm{TM}}$.

Para verificar se há diferença estatística significante entre o nível de satisfação dos alunos e o turno em que estão matriculados, por se tratar de uma variável de razão, a satisfação foi avaliada a partir de um teste-t para diferença de médias. Conforme exposto na Tabela $1 \mathbf{0}$, a um nível de significância de 0,05 , não foi possível rejeitar a hipótese nula (H0), concluindo-se que não existe diferença significativa entre o nível de satisfação dos alunos matriculados no turno diurno e os alunos matriculados no turno noturno. Diante desse resultado, optou-se por trabalhar com os dois cursos em conjunto sem separar a amostra segundo o turno.

Em relação ao sexo dos estudantes, observou-se uma freqüência de 115 homens (51\%) e 109 mulheres (49\%). O teste $t$ revelou que, em média, não há diferença na satisfação com o curso entre homens e mulheres $(t=0,502$, não significativo a 5\%). A idade média dos respondentes é de 23 anos, estando a maioria cursando o segundo e o quarto semestre, $27 \%$ e $25 \%$, respectivamente.

\subsection{Validação individual dos construtos}

Para a validação individual dos construtos foi realizada a Análise Fatorial Confirmatória e os relacionamentos entre as variáveis observadas e os seus construtos foram estimados utilizando o método da máxima verossimilhança. Os resultados obtidos em relação aos índices de ajuste do modelo e confiabilidade podem ser visualizados na Tabela $2 \mathbf{0}$.

Partiu-se do modelo originalmente proposto para se obterem os índices de ajuste iniciais. Caso o modelo não apresentasse valores satisfatórios para o seu nível de confiabilidade ou índices de ajuste abaixo do recomendado pela literatura, optou-se por retirar aquelas variáveis que apresentassem coeficientes padronizados mais baixos.

O construto inicialmente analisado foi o Envolvimento do Professor, formado por sete variáveis. Após o cálculo de todos os índices de ajuste considerados para o modelo verificou-se que o teste Qui-quadrado é significativo $(p=0,000)$, indicando, assim, uma diferença entre a matriz observada e a matriz original. Algumas medidas de ajuste também apresentaram valores fora dos limites aceitáveis: NFI e NNFI inferiores a 0,9 e o RMSEA superior a 0,08.

Tabela 1 Teste t para diferença de média de satisfação dos alunos nos dois turnos

\begin{tabular}{l|c|c|c|c|c} 
Turno & N & $\begin{array}{c}\text { Média de } \\
\text { Satisfação }\end{array}$ & $\begin{array}{c}\text { Desvio } \\
\text { Padrão }\end{array}$ & T & Sig. \\
\cline { 1 - 3 } Diurno & 85 & 70,85 & 13,87 & \multirow{2}{*}{0,846} & 0,449 \\
\hline Noturno & 139 & 68,52 & 15,25 & 0,5 \\
\hline
\end{tabular}

Tabela 2 Resultado dos índices de ajuste

\begin{tabular}{|c|c|c|c|c|c|c|c|c|c|c|}
\hline \multirow{3}{*}{$\begin{array}{l}\text { Índices de } \\
\text { Ajuste }\end{array}$} & \multicolumn{10}{|c|}{ Construtos } \\
\hline & \multicolumn{2}{|c|}{$\begin{array}{l}\text { Envolvimento } \\
\text { do Professor }\end{array}$} & \multicolumn{2}{|c|}{$\begin{array}{c}\text { Interesse } \\
\text { do Estudante }\end{array}$} & \multicolumn{2}{|c|}{$\begin{array}{c}\text { Interação } \\
\text { Estudante- } \\
\text { Professor }\end{array}$} & \multicolumn{2}{|c|}{$\begin{array}{l}\text { Demandas } \\
\text { do Curso }\end{array}$} & \multicolumn{2}{|c|}{$\begin{array}{c}\text { Organização } \\
\text { do curso }\end{array}$} \\
\hline & Inicial & Final & Inicial & Final & Inicial & Final & Inicial & Final & Inicial & Final \\
\hline \multirow{2}{*}{ Qui-quadrado } & 52,69 & 7,149 & 21,031 & 14,869 & 34,333 & 2,624 & 68,551 & 0,203 & 15,907 & 7,712 \\
\hline & $p=0,000$ & $p=0,210$ & $p=0,013$ & $p=0,011$ & $p=0,002$ & $p=0,269$ & $p=0,000$ & $p=1,000$ & $p=0,069$ & $p=0173$ \\
\hline $\begin{array}{l}\text { Graus de } \\
\text { Liberdade }\end{array}$ & 14 & 5 & 9 & 5 & 14 & 2 & 10 & 0,652 & 9 & 5 \\
\hline $\mathrm{GFI}$ & 0,938 & 0,987 & 0,969 & 0,974 & 0,958 & 0,994 & 0,916 & 0,999 & 0,978 & 0,987 \\
\hline $\mathrm{CFI}$ & 0,915 & 0,993 & 0,961 & 0,963 & 0,937 & 0,997 & 0,439 & 1,000 & 0,975 & 0,988 \\
\hline $\mathrm{NFI}$ & 0,889 & 0,978 & 0,935 & 0,947 & 0,900 & 0,989 & 0,426 & 0,996 & 0,946 & 0,968 \\
\hline $\mathrm{NNFI}$ & 0,873 & 0,986 & 0,935 & 0,927 & 0,906 & 0,992 & 0,159 & 1,050 & 0,959 & 0,977 \\
\hline RMR & 0,052 & 0,026 & 0,045 & 0,040 & 0,054 & 0,017 & 0,125 & 0,011 & 0,040 & 0,031 \\
\hline RMSEA & 0,111 & 0,044 & 0,077 & 0,094 & 0,081 & 0,037 & 0,162 & 0,000 & 0,059 & 0,049 \\
\hline $\begin{array}{l}\text { Alpha de } \\
\text { Crombach }\end{array}$ & 0,814 & 0,785 & 0,772 & 0,774 & 0,743 & 0,774 & 0,444 & 0,359 & 0,764 & 0,754 \\
\hline
\end{tabular}


Sendo assim, diante desses resultados iniciais decidiu-se por modificar o modelo e retiraram-se as variáveis Q. 15 e Q. 16.

O modelo final apresentou um nível satisfatório para o teste Qui-quadrado $(p=0,210)$, que passou a ser não significativo. Todos os demais índices de ajuste apresentaram resultados melhores do que os valores mínimos sugeridos, inclusive aqueles que mostraram valores abaixo do sugerido no modelo inicial ( $\mathrm{NFI}=0,978, \mathrm{NNFI}=0,986$, RMSEA $=0,044)$. Em relação à confiabilidade, apesar do valor do Alfa de Crombach ter sido menor, ainda pode-se considerar o novo valor $(0,785)$ como satisfatório.

O construto Interesse do Estudante era formado inicialmente por seis variáveis. Verificou-se que o modelo apresentou para o teste Qui-quadrado um valor de $p=0,013$, indicando, em uma primeira análise, um valor significativo. Todos os índices de ajustes absolutos e comparativos ficaram acima dos valores mínimos exigidos. O Alfa de Crombach também apresentou um valor aceitável $(0,772)$. Foram feitas simulações que demonstraram que nem mesmo a retirada do construto daquelas variáveis cujos coeficientes padronizados apresentavam valores mais baixos melhorava o ajuste do modelo. Sendo assim, optou-se por manter o modelo como descrito originalmente. A literatura mostra que o teste Qui-Quadrado é influenciado pelo tamanho amostral e sugere uma correção pelos graus de liberdade (HAIR et al., 2005; KLINE, 1998). A divisão do valor do qui-quadrado pelos graus de liberdade $\left(\chi^{2} / \mathrm{GL}\right)$ teve como resultado o valor de 2,337 (21,031/9), de acordo com Kline (1998) uma razão menor do que três é considerada aceitável.

Analisou-se, em seguida, o construto Interação Professor-Estudante. O modelo original apresentou um teste de Qui-quadrado expressivo $(p=0,002)$, indicando a existência de uma diferença significativa entre a matriz observada e a matriz estimada. Praticamente todos os índices de ajuste apresentaram valores melhores do que os resultados mínimos exigidos; apenas o índice de ajuste absoluto RMSEA indicou um valor pouco acima do mínimo exigido
$(0,081)$. O Alfa de Crombach do construto, por sua vez, apresentou um valor satisfatório $(0,743)$.

Assim, retiraram-se do modelo original as variáveis cujos coeficientes padronizados apresentavam os menores valores. Excluíram-se, dessa forma: Q. 28 (C.P.=0,441), Q. 29 (C.P. $=0,453)$ e Q. 30 (C.P. $=0,246$ ). Calcularam-se os índices para o novo modelo. O Qui-quadrado apresentou uma redução expressiva, passando a não ser significativo $(p=0,269)$. Os demais índices de ajuste absolutos e comparativos apresentaram valores adequados, bem como 0 Alfa de Crombach, que revelou uma melhora no seu resultado $(0,774)$.

O modelo inicial do construto Demandas do Curso contava com seis vaiáveis. Após calcularem-se os índices de ajuste absolutos e comparativos, verificou-se que apenas o GFI apresentou um valor dentro do aceitável, 0,916; todos os demais índices, assim como o Alfa de Crombach $(0,444)$, apresentaram valores insatisfatórios. Procurouse, então, criar novas combinações entre as variáveis, no entanto, nenhuma delas apresentou um Alfa de Crombach superior a 0,7. Dessa forma, optou-se por retirar esse construto do modelo.

Por fim tem-se o construto Organização do Curso, cujo modelo original era formado por seis variáveis. O modelo apresentou um teste de Qui-quadrado não significativo $(p=0,069)$. Todos os demais índices de ajuste absolutos e comparativos apresentaram níveis adequados. O Alfa de Crombach também se mostrou satisfatório 0,764. Seguindo o proposto por Garver e Mentzer (1999) excluiu-se a variável Q. 41 por apresentar um coeficiente padronizado inferior a 0,5 $(\mathrm{Q} \cdot 41=0,47)$. Após retirar as variáveis, os valores dos índices de ajuste melhoraram um pouco; o Alfa de Crombach, no entanto apresentou uma pequena piora, passando de 0,764 para 0,719, mas mesmo assim o valor se manteve acima do limite recomendável.

Um resumo dos coeficientes padronizados e da significância das variáveis formadoras dos construtos finais pode ser visualizado na Tabela $3 \mathbf{0}$.

Tabela 3 | Coeficientes padronizados e significância

\begin{tabular}{|c|c|c|c|c|c|c|c|}
\hline Construto & Variáveis & $\begin{array}{l}\text { Coeficiente } \\
\text { Padronizado }\end{array}$ & z & Construto & Variáveis & $\begin{array}{l}\text { Coeficiente } \\
\text { Padronizado }\end{array}$ & Z \\
\hline \multirow{5}{*}{$\begin{array}{l}\text { Envolvimento } \\
\text { do professor }\end{array}$} & Q. 11 & 0,776 & 1 & & & & \\
\hline & Q. 12 & 0,820 & 10,697 ** & \multirow{4}{*}{$\begin{array}{l}\text { Interação } \\
\text { professor- } \\
\text { estudante }\end{array}$} & Q. 24 & 0,690 & 1 \\
\hline & Q. 13 & 0,527 & $7,294 * *$ & & Q. 25 & 0,700 & $8,190 * *$ \\
\hline & Q. 14 & 0,506 & $6,995 * *$ & & Q. 26 & 0,585 & $7,172^{* *}$ \\
\hline & Q. 17 & 0,640 & $8,878^{* *}$ & & Q. 27 & 0,751 & $8,440^{* \star}$ \\
\hline \multirow{5}{*}{$\begin{array}{l}\text { Interesse } \\
\text { do estudante }\end{array}$} & Q. 18 & 0,603 & 1 & \multirow{5}{*}{$\begin{array}{l}\text { Organização } \\
\text { do curso }\end{array}$} & Q. 37 & 0,593 & $6,601^{* *}$ \\
\hline & Q. 19 & 0,719 & $7,506^{* *}$ & & Q. 38 & 0,791 & $7,516^{* *}$ \\
\hline & Q. 20 & 0,588 & $6,642 * *$ & & Q. 39 & 0,514 & $5,951^{* *}$ \\
\hline & Q. 21 & 0,630 & $6,958 * *$ & & Q. 40 & 0,601 & $6,658^{* *}$ \\
\hline & Q. 23 & 0,679 & $7,286^{* *}$ & & Q. 42 & 0,592 & 1 \\
\hline
\end{tabular}

1 valor de z não calculado, pois o parâmetro foi arbitrariamente fixado em 1,0. 


\subsection{Validação do modelo proposto}

Após a validação individual dos construtos, procurouse avaliar as hipóteses propostas no modelo. Assim, o modelo individual dos construtos a ser considerado para o estudo pode ser visualizado na Figura $2 \mathbf{0}$.

Empregou-se a estratégia de aprimoramento do modelo. Os critérios utilizados para a realização dos ajustes foram, em primeiro lugar, retirar os coeficientes de regres- são não significativos. Em seguida procurou-se estabelecer correlações entre os erros das variáveis pertencentes a um mesmo construto. Por fim, optou-se por adicionar correlações não previstas inicialmente. Procurou-se relacionar os erros daquelas variáveis que, preferencialmente, pertenciam a um mesmo construto; as demais relações sugeridas pelo $A \operatorname{mos}^{\text {TM }}$ só foram aceitas quando apresentavam justificativa do ponto de vista teórico. O processo de retirada

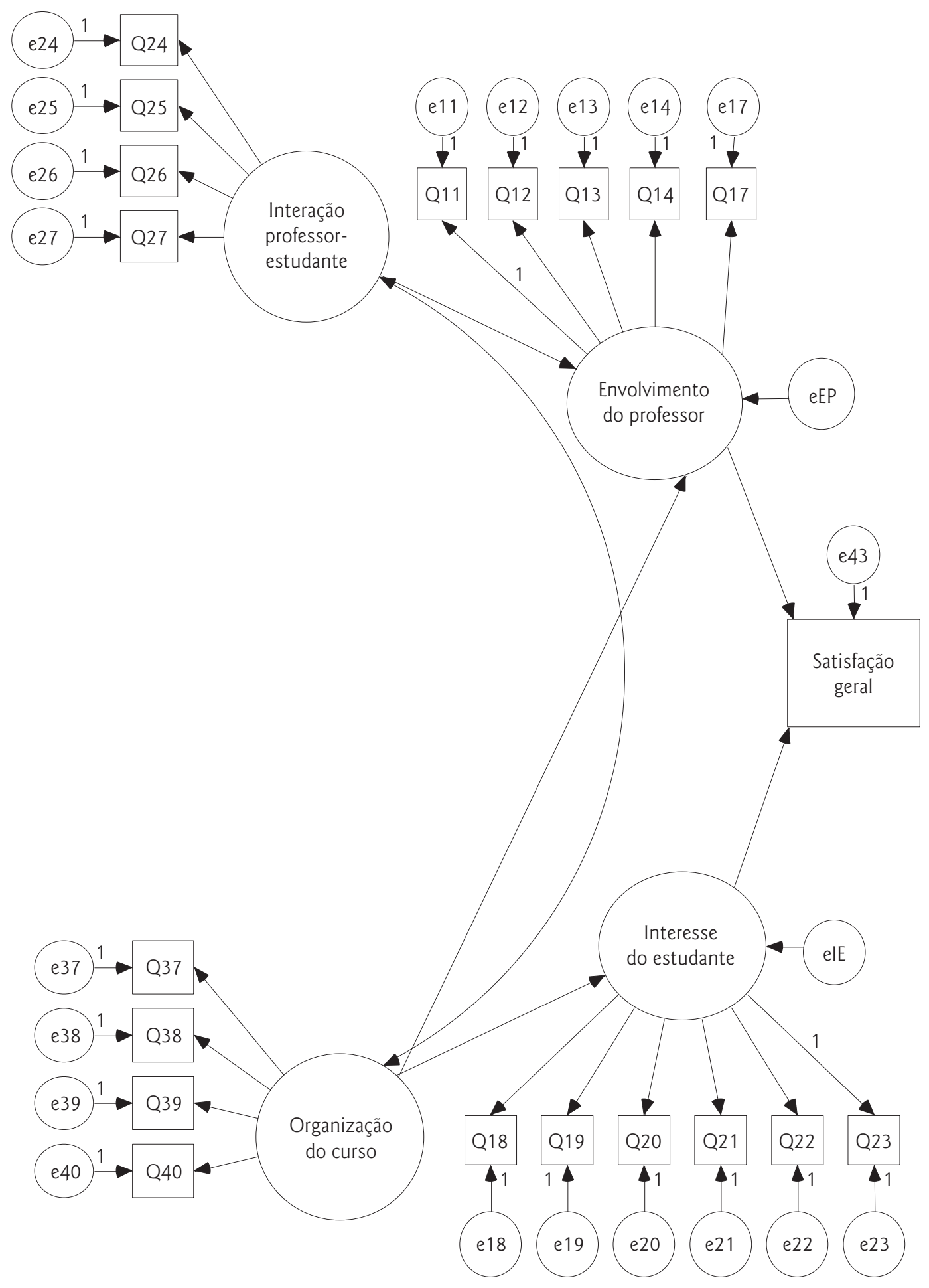

Figura 2 || Modelo proposto final 
envolveu a eliminação individual de cada uma das relações não significativas tendo em vista que, a cada retirada havia a necessidade de uma re-estimação do modelo devido às modificações nos coeficientes e na significância das demais variáveis do modelo.

Sendo assim, retirou-se, em primeiro lugar, a hipótese $\mathrm{H} 2$, que estabelecia a relação entre os construtos Interação Professor-Estudante e Interesse do Estudante, tendo em vista que o seu coeficiente não era significativo $(0,257)$. Em seguida, seguindo o sugerido pelo $A \operatorname{mos}^{\mathrm{TM}}$, procurou-se estabelecer correlações entre os erros das variáveis. Depois de re-estimar os coeficientes para cada nova correlação incorporada, consideraram-se os seguintes erros correlacionados apresentados na Tabela $4 \boldsymbol{0}$.

Após a retirada da relação não significativa existente e da inserção das correlações sugeridas, o modelo final aprimorado apresentou, conforme se pode visualizar na Tabela $5 \mathbf{0}$, os seguintes índices de ajuste.

O modelo final ajustado apresentou um qui-quadrado significativo $(p=0,000)$, contudo a relação $\chi^{2} /$ graus de liberdade apresentou razão menor que $3(1,86)$, índice considerado aceitável (KLINE, 1998; HAIR et al., 2005). Em relação aos outros índices, o GFI $(0,889)$, o NFI $(0,820)$ e o NNFI $(0,889)$ apresentaram índices menores que os limites desejáveis. Para os demais índices os valores apresentados foram considerados satisfatórios.

Os coeficientes padronizados e os seus respectivos graus de significância encontrados para as hipóteses são apresentados na Tabela 60 .

Através dos coeficientes padronizados e dos seus respectivos graus de significância encontrados, é possível responder às hipóteses levantadas neste estudo. Portanto, pode-se afirmar que:

- O construto Interação Professor-Estudante influencia positivamente o construto Envolvimento do Professor $(\mathrm{H} 1)$.

- O construto Organização do Curso influencia positivamente o construto Envolvimento do Professor (H5).

- O construto Organização do Curso influencia positivamente o construto Interesse do Estudante no curso (H6).

- O construto Envolvimento do Professor influencia positivamente a Satisfação Geral do estudante em relação ao curso $(\mathrm{H} 7)$.

- O construto Interesse do Estudante influencia positivamente o grau de Satisfação Geral do estudante em relação ao curso $(\mathrm{H} 8)$.

As hipóteses cujos coeficientes padronizados não apresentaram valores significantes e, portanto, foram excluídas do modelo são:

- O construto Interação Professor-Estudante não conduzirá a um nível maior de Interesse do Estudante no curso $(\mathrm{H} 2)$. Hipótese não significante.

- O construto Demandas do Curso não conduzirá a um baixo nível, percebido, do Envolvimento do Professor (H3). Hipótese não significante.

- O construto Demandas do Curso conduzirá a um nível mais baixo de Interesse do Estudante no curso (H4). Hipótese não significante.

Tabela 4 || Correlação entre os erros

\begin{tabular}{|c|c|}
\hline Correlação entre os erros & Coeficiente \\
\hline $\begin{array}{l}\text { Interação Estudante-Professor - } \\
\text { Organização do curso }\end{array}$ & 0,652 ** \\
\hline e.19-e.18 & $0,278 * *$ \\
\hline e. $11-\mathrm{e} .12$ & 0,361 ** \\
\hline e. $40-e .38$ & $0,294 * *$ \\
\hline e. $22-\mathrm{e} .23$ & $0,196 * *$ \\
\hline e.38-e.43 & $0,281 * *$ \\
\hline
\end{tabular}

** significativo ao nível de $1 \%$.

Tabela 5 I Índices de ajuste - Modelo final aprimorado

\begin{tabular}{c|c} 
Índices de Ajuste & Valores \\
Qui-quadrado $\left(\chi^{2}\right)$ & 296,961 \\
\cline { 2 - 2 } & $\mathrm{p}=0,000$ \\
\hline Graus de Liberdade & 160 \\
\hline $\mathrm{GFI}$ & 0,889 \\
\hline $\mathrm{CFI}$ & 0,906 \\
\hline $\mathrm{NFI}$ & 0,82 \\
\hline $\mathrm{NNFI}$ & 0,889 \\
\hline RMR & 0,059 \\
\hline RMSEA & 0,062
\end{tabular}


Tabela 6 - Coeficientes padronizados e significância das hipóteses

\begin{tabular}{l|c|c}
\multicolumn{1}{c|}{ Hipótese } & $\begin{array}{c}\text { Coeficientes } \\
\text { Padronizados }\end{array}$ & $\mathbf{z}$ \\
\hline $\begin{array}{l}\text { Interesse do Estudante - } \\
\text { Interação Professor-Estudante }\end{array}$ & 0,243 & $2,16^{*}$ \\
\hline $\begin{array}{l}\text { Interesse do Estudante - } \\
\text { Organização do Curso }\end{array}$ & 0,633 & $5,49^{* *}$ \\
\hline $\begin{array}{l}\text { Envolvimento do Professor - } \\
\text { Organização do Curso }\end{array}$ & 0,588 & $4,4^{* *}$ \\
\hline $\begin{array}{l}\text { Satisfação Geral - } \\
\text { Interesse do Estudante }\end{array}$ & 0,347 & $4,32^{* *}$ \\
\hline $\begin{array}{l}\text { Satisfação Geral - } \\
\text { Envolvimento do Professor }\end{array}$ & 0,406 & $5,06^{* *}$ \\
\hline
\end{tabular}

1 valor de $z$ não calculado, pois o parâmetro foi arbitrariamente fixado em 1,0.

*, **, indicam, respectivamente, significativos ao nível de $5 \%$ e $1 \%$.

Das oito hipóteses inicialmente propostas, cinco apresentaram coeficientes estatisticamente significantes ao nível de, pelo menos, 5\%: H1, H5, H6, H7 e H8. As hipóteses $\mathrm{H} 2, \mathrm{H} 3$ e $\mathrm{H} 4$ revelaram coeficientes não significativos a 5\%. Cabe ressaltar que a hipótese $\mathrm{H} 4$ corroborou com o resultado encontrado por Paswan e Young (2002), já que elas também não apresentaram significância.

\section{CONSIDERAC̣ÕES FINAIS}

A satisfação é um fator primordial para garantir a motivação do discente ao longo da sua formação acadêmi$\mathrm{ca}$, interferindo no aproveitamento do seu aprendizado e, conseqüentemente, na competência dos profissionais que serão inseridos no competitivo mercado de trabalho. Logo, compreender quais as variáveis que influenciam a satisfação dos acadêmicos é fundamental para as Instituições de Ensino Superior que desejam manter a qualidade dos serviços prestados. Tendo como objetivo avaliar quais os fatores que determinam a satisfação geral dos alunos de Ciências Contábeis da Universidade Federal de Santa Maria, o presente trabalho partiu dos construtos propostos no modelo de equações estruturais de Paswan e Young (2002).

Após alguns ajustes no modelo inicial, obteve-se um modelo adequado para mensurar a Satisfação Geral dos estudantes de uma Instituição de Ensino Superior. Oito hipóteses foram testadas na pesquisa, sendo que dessas seis foram obtidas no estudo de Paswan e Young (2002) e duas foram formuladas pelos autores para verificar se os construtos do modelo inicial podem explicar a Satisfação Geral dos estudantes de uma IES em relação ao seu curso. Os resultados encontrados indicam que as hipóteses 2, 3 e 4 não são significantes. O construto Interação ProfessorEstudante não influencia positivamente o construto Interesse do Estudante $(\mathrm{H} 2)$. Não foi validada a existência do construto Demandas do Curso, o que implicou na retirada do modelo inicial das hipóteses 3 e 4: o construto Deman- das do Curso não conduzirá a um baixo nível, percebido, do Envolvimento do Professor (H3), o construto Demandas do Curso conduzirá a um nível mais baixo de Interesse do Estudante no curso $(\mathrm{H} 4)$.

A retirada desse do construto Demandas do Curso, presente no modelo inicial é justificada pelo fato de os índices de ajuste absolutos e comparativos, com exceção apenas para o GFl, apresentarem valores insatisfatórios. O Alfa de Crombach também possuía um valor inaceitável, abaixo de 0,7 , indicando que as variáveis não formam um construto. Cabe ressaltar que foram feitas simulações para avaliar a possibilidade de essas variáveis influenciarem os construtos Envolvimento do Professor e Interesse do Estudante, mas nenhuma relação mostrou-se significativa.

Assim, o modelo final encontrado é composto por quatro construtos - Envolvimento do Professor, Interesse do Estudante, Interação Professor-Estudante e Organização do Curso - e dezoito variáveis. A pesquisa demonstrou que o modelo é adequado para mensurar a Satisfação Geral dos estudantes do Curso de Ciências Contábeis da UFSM, uma vez que se comprovou que os construtos Envolvimento do Professor e Interesse do Estudante influenciam positivamente a Satisfação Geral do estudante em relação ao curso. Entretanto, a validação do modelo como um instrumento de avaliação de satisfação de alunos carece de mais estudos. Sugere-se, portanto, a aplicação do instrumento em outros cursos e instituições. 


\section{Referências}

ANDERSON, J. C.; GERBING, D. W. Structural equation modeling in practice: a review and recommended two-step approach. Psychological Bulletin, v. 103, n. 3, p. 411-423, 1988.

BRASIL. Lei ordinária n. 9.394, de 20 de dezembro de 1996.

CASHIN, W. E. Student ratings of teaching: a summary of the research. IDEA Paper, n. 20, Kansas State University, 1988.

Student ratings of teaching: the research revisited. IDEA Paper, n. 32, Kansas State University, 1995.

CHURCHILL Jr., G. A. A paradigm of developing better measures of marketing constructs. Journal of Marketing Research, v. 16, p. 64-73, 1979.

CLAYSON, D. E.; HALEY, D. A. Student evaluations in marketing: what is actually being measured? Journal of Marketing Education, v. 12, n. 3, p. 9-17, 1990.

CODA, R.; SILVA, D. Sua escola de administração é uma excelente escola para se estudar? descobrindo dimensões de alunos em cursos de administração: uma contribuição metodológica. In: ENCONTRO NACIONAL DOS PROGRAMAS DE PÓS-GRADUAÇÃO EM ADMINISTRAÇÃO, 28., 2004, Curitiba. Anais... Curitiba: ENANPAD 2004. CD ROM.

DE TONI, D. et al. Análise da satisfação com instituições de educação superior e imagem: comparando instrumentos. In: ENĆONTRO NACIONAL DOS PROGRAMAS DE PÓS-GRADUAÇÃO EM ADMINISTRAÇÃO, 30., 2006, Salvador. Anais... Salvador: ENANPAD 2006. CD ROM.

GARVER, N. S.; MENTZER, J. T. Logistics research methods: employing structural equation modeling to test for construct validity. Journal of Business Logistics, v. 20, n. 1, p. 33-57, 1999.

GONÇALVES FILHO, C.; GUERRA, R. S.; MOURA, A. Mensuração de satisfação, qualidade, lealdade, valor e expectativa em instituições de ensino superior: um estudo do modelo ACSI através de equações estruturais. In: ENCONTRO NACIONAL DOS PROGRAMAS DE PÓSGRADUAÇÃO EM ADMINISTRAÇÃO, 27., 2003, Atibaia. Anais... Atibaia: ENANPAD 2003. CD ROM.

GRUNENWALD, J. P.; ACKERMAN, L. A modified delphi approach for the development of student evaluations of faculty teaching. Journal of Marketing Education, v. 8, n. 2, p. 32-38, 1986.

HAIR, J. F. et al. Análise multivariada de dados. Porto Alegre: Bookman, 2005.

KLINE, R. B. Principles and practice of structural equation modeling. New York: The Guilford Press, 1998, 354 p.

MALHOTRA, N. K. Pesquisa de marketing: uma orientação aplicada. Porto Alegre: Bookman, 2001.

MARKS, R. B. Determinants of student evaluations an indicators of global measures of instructor and course value. Journal of Marketing Education, v. 22, n. 2, p. 108-119, 2000.

MARSH, H.W. The use of path analysis to estimate teacher and course effects in student rating's of instructional effectiveness. Applied Psychological Measurement, v. 6, p. 47-59, 1982.

PASWAN, A. K.; YOUNG, J. A. Student evaluation of instructor: a nomelogical investigation using struuctural euation modeling. Journal of Marketing Education, v. 24, n. 3, p. 193-202, 2002.

PEDHARZUR, E. J.; SCHMELKIN, L. P. Measurement, design, and analysis: an integrated approach. New Jersey: Lawrence Erlbaum, 1991. SCHUMACKER, R. E.; LOMAX, R. G. A beginner's guide to structural equation modeling. New Jersey: Lawrence Erlbaum, 1996, 286 p. SOUKI, G. Q.; PEREIRA, C. A. Satisfação, motivação e comprometimento de estudantes de administração: um estudo com base nos atributos de uma instituição de ensino superior. In: ENCONTRO NACIONAL DOS PROGRAMAS DE PÓS-GRADUAÇÃO EM ADMINISTRAÇÃO, 28., 2004, Curitiba. Anais... Curitiba: ENANPAD 2004. CD ROM.

WALTER, S.; TONTINI, G.; DOMINGUES, M. Identificando oportunidades de melhoria em um curso superior através da análise da satisfação dos alunos. In: ENCONTRO NACIONAL DE PROGRAMAS DE PÓS-GRADUAÇÃO EM ADMINISTRAÇÃO. 29., 2005, Rio de Janeiro. Anais... Rio de Janeiro: ENANPAD 2005. CD ROM.

\section{NOTA - Endereço dos autores}

Universidade Federal de Santa Maria Departamento de Ciências Administrativas Rua Floriano Peixoto, 1184, sala 502

Santa Maria - RS

97015-372

Av. Loureiro da Silva, 1500, ap. 610

Porto Alegre - RS

90050-240
Rua Tuiuti, 1835, ap. 204

Santa Maria - RS

97015-663 


\section{ANEXO 1: TERCEIRO BLOCO DO QUESTIONÁRIO, DESENVOLVIDO A PARTIR DO MODELO DE PASWAN E YOUNG (2002)}

\begin{tabular}{|c|c|c|c|c|c|}
\hline \multirow[b]{2}{*}{ 11. Os professores apresentam o conteúdo de forma entusiasmada. } & \multicolumn{3}{|c|}{ Discordo Totalmente } & \multicolumn{2}{|c|}{ Concordo Totalmente } \\
\hline & 1 & 2 & 3 & 4 & 5 \\
\hline 12. Ao ensinar, os professores parecem interessados. & 1 & 2 & 3 & 4 & 5 \\
\hline $\begin{array}{l}\text { 13. Os exemplos utilizados pelos professores ajudam na compreensão do } \\
\text { conteúdo. }\end{array}$ & 1 & 2 & 3 & 4 & 5 \\
\hline 14. Os professores procuram saber se o estudante aprendeu o conteúdo. & 1 & 2 & 3 & 4 & 5 \\
\hline 15. Os professores procuram relacionar a teoria com a prática profissional. & 1 & 2 & 3 & 4 & 5 \\
\hline 16. Os professores são qualificados profissionalmente. & 1 & 2 & 3 & 4 & 5 \\
\hline $\begin{array}{l}\text { 17. De uma maneira geral, avalio de forma positiva o desempenho dos } \\
\text { professores. }\end{array}$ & 1 & 2 & 3 & 4 & 5 \\
\hline 18. Você se sente interessado em aprender o conteúdo do curso. & 1 & 2 & 3 & 4 & 5 \\
\hline 19. Geralmente, você fica atento em sala de aula. & 1 & 2 & 3 & 4 & 5 \\
\hline 20. Você sente que o curso Ihe desafia intelectualmente. & 1 & 2 & 3 & 4 & 5 \\
\hline 21. Você acredita estar se tornando mais competente na sua área de estudo. & 1 & 2 & 3 & 4 & 5 \\
\hline 22. Geralmente você participa de discussões em sala de aula. & 1 & 2 & 3 & 4 & 5 \\
\hline 23. Avalio de forma positiva o meu desempenho ao longo do curso. & 1 & 2 & 3 & 4 & 5 \\
\hline 24. O professor encoraja o estudante a expressar sua opinião. & 1 & 2 & 3 & 4 & 5 \\
\hline 25. O professor é receptivo a novas idéias e diferentes pontos de vista. & 1 & 2 & 3 & 4 & 5 \\
\hline 26. Os estudantes têm oportunidade para fazerem perguntas. & 1 & 2 & 3 & 4 & 5 \\
\hline 27. Os professores geralmente estimulam a discussão em sala de aula. & 1 & 2 & 3 & 4 & 5 \\
\hline $\begin{array}{l}\text { 28. Os professores disponiblizam a seus alunos materiais de estudo sobre } \\
\text { as aulas dadas. }\end{array}$ & 1 & 2 & 3 & 4 & 5 \\
\hline 29. Os professores avaliam seus alunos com precisão e justiça. & 1 & 2 & 3 & 4 & 5 \\
\hline $\begin{array}{l}\text { 30. É permitido aos alunos contatar os professores fora do ambiente da } \\
\text { Universidade. }\end{array}$ & 1 & 2 & 3 & 4 & 5 \\
\hline 31. Os professores abordam muitos conteúdos (além do necessário). & 1 & 2 & 3 & 4 & 5 \\
\hline 32. Os professores apresentam o conteúdo muito rapidamente. & 1 & 2 & 3 & 4 & 5 \\
\hline $\begin{array}{l}\text { 33. Os trabalhos realizados consomem muito tempo em relação ao conheci- } \\
\text { mento que agregam. }\end{array}$ & 1 & 2 & 3 & 4 & 5 \\
\hline 34. Você acha as leituras indicadas muito difíceis. & 1 & 2 & 3 & 4 & 5 \\
\hline 35. Os materiais utilizados pelos professores são de boa qualidade. & 1 & 2 & 3 & 4 & 5 \\
\hline $\begin{array}{l}\text { 36. Os professores trabalham todos os conteúdos previstos na ementa das } \\
\text { disciplinas. }\end{array}$ & 1 & 2 & 3 & 4 & 5 \\
\hline 37. Os professores relacionam os conteúdos de forma sistemática. & 1 & 2 & 3 & 4 & 5 \\
\hline 38. O curso (as disciplinas) é bem organizado. & 1 & 2 & 3 & 4 & 5 \\
\hline $\begin{array}{l}\text { 39. Você considera fácil fazer anotações das apresentações realizadas pelo } \\
\text { professor. }\end{array}$ & 1 & 2 & 3 & 4 & 5 \\
\hline 40. A seqüência da grade curricular é apresentada de maneira adequada. & 1 & 2 & 3 & 4 & 5 \\
\hline $\begin{array}{l}\text { 41. Os funcionários, geralmente, asseguram o bom andamento operacional } \\
\text { do curso. }\end{array}$ & 1 & 2 & 3 & 4 & 5 \\
\hline 42. De uma maneira geral o curso atende as minhas expectativas. & 1 & 2 & 3 & 4 & 5 \\
\hline
\end{tabular}

